\title{
Turismo: tendências de evolução
}

\section{Dina Maria Ramos ${ }^{1}$ e Carlos Manuel Costa ${ }^{2}$}

1 Investigadora de pós- doutoramento da Universidade de Aveiro. Doutora em Turismo e Suficiência Investigadora em "Novos recursos e Sustentabilidade em Turismo" pela Universidade de Salamanca (Espanha), Licenciada em Gestão pela Universidade Internacional de Lisboa. Membro da Unidade de Investigação em Governança, Competitividade e Políticas Públicas (GOVCOPP) na Universidade de Aveiro, Portugal. E-mail: dinaramos@ua.pt

2 Doutor e Mestre em Turismo pela Universidade de Surrey (Reino Unido) e licenciado em Planeamento Regional e Urbano pela Universidade de Aveiro. Professor catedrático e diretor do departamento de Economia, Gestão, Engenharia Industrial e Turismo (DEGEIT) da universidade de Aveiro, Portugal. E-mail: ccosta@ua.pt

RESUMO: A evolução do Turismo está intrinsecamente ligada ao desenvolvimento mundial. A transmissão de cultura entre os povos, o conhecimento da história e a língua são fundamentos de um paradigma moderno de gestão e planeamento baseado nas pessoas, no património e na cultura. O consumo e as tendências dos consumidores cada vez mais informados, evolui para a procura de experiências personalizadas e que lhe permitam diferenciar-se da população em geral. O mundo está a mudar e o Turismo está a mudar o mundo, a globalização assente numa competitividade sustentável será um dos pilares do futuro turístico a nível mundial. O presente artigo pretende efetuar uma breve abordagem histórica à evolução do Turismo e aos aspetos conceptuais que perspetivam as tendências de evolução turística.

Palavras chave: Turismo; Desenvolvimento; Tendências do Turismo

\section{Tourism: Evolution Trends}

\begin{abstract}
The development of Tourism is intrinsically linked to global development. The transmission of culture between people, knowledge of history and language is source of a modern paradigm of management and planning based on people, heritage and culture. The consumption and trends in becoming increasingly empowered consumers, evolving demand for personalized experiences and allowing us to differentiate ourselves from the general population. The world is changing and Tourism is changing the world as well (Costa, C. 2016), therefore, globalization based on a sustainable competitiveness will be a cornerstone of future tourism worldwide. This article aims to provide a brief historical overview approach to the development of tourism and conceptual aspects that represents trends of tourism development.
\end{abstract}

Keywords: Tourism; Development; Trends in Tourism

\section{INTRODUÇÃO}

O Turismo é um dos principais sectores em termos económicos para os países desenvolvidos ou em vias de desenvolvimento. Desde tempos mais remotos o Turismo evolui, e, começando por ser "permitido" inicialmente a classes mais elitistas, e muitas vezes como parte de um processo de cura, chega à idade moderna como um dado adquirido e possível de vivenciar por toda a população.

O desenvolvimento desta investigação encontra-se estruturado de forma a res- 
ponder a génese da questão colocada, perante a formulação de um problema que reside na aferição dos desafios decorrentes da necessidade de perceber as especificações próprias do setor turístico e os aspetos conceptuais que nos permitem perspetivar as tendências e evolução turística. Valorizou-se a revisão de literatura, que se vislumbra crucial para a discussão desta temática.

Esta investigação aborda uma análise histórica de evolução e contextualização do Turismo. Estuda-se e desenvolve-se com enfoque geral, no contexto mundia no caso particular de Portugal, em termos de perspetiva, estatística e da sua evolução. O cariz teórico foi desenvolvido com o objetivo conclusivo de avaliação da evolução e projeção futura do Turismo.

\section{ANÁLISE HISTÓRICA DO TURISMO}

\subsection{Evolução e Contextualização Geral}

As principais características do Turismo aquando do seu surgimento assemelhamse às que encontramos nos nossos dias. As várias formas de lazer em Turismo remontam a tempos tão longínquos como os impérios da Babilónia ou o império Egípcio.

Uma das primeiras manifestações conhecidas do Turismo remonta ao Séc. VI a.C., por ocasião da realização de festivais religiosos nas cidades, aos quais as pessoas confluíam para ver as artes, onde existiam vendedores de comidas e bebidas, lembranças, etc. (Holloway, 1994). As atividades de lazer eram procuradas por classes mais elitistas desde as primeiras civilizações. Torkildsen (1992) cita Aristóteles (livro 1 de Política), que define Lazer como: "O tempo livre da necessidade de trabalhar... Lazer leva a iluminação estética, espiritual ou intelectual através de uma busca de entendimento".

Na Grécia, 2000 anos antes de Cristo, faziam-se viagens para visitar "deuses de cura", muitas delas efetuadas por mar, acentuando a prosperidade dos portos marítimos. A Grécia tornou-se um destino importante de viagem no séc. $V$ a.C., com a construção da acrópole de Atenas do Parthenon e de várias pousadas de alojamento próximas dos grandes centros ou dos portos marítimos, que procuravam satisfazer as necessidades dos viajantes ( Holloway,1994). A moeda Romana era aceite como comum e o latim era a língua falada. Os Romanos foram os primeiros a introduzir os "guidebooks", que listavam os hotéis que tinham selo de qualidade. Esta era uma época em que existia muita burocracia associada ao ato de viajar. As pessoas precisavam de ter uma autorização para tal e o que adquirissem durante a viagem era frequentemente sujeito a impostos. Durante o império Romano, apareceu também o Turismo doméstico, com o surgimento de segundas residências, principalmente na Primavera como forma de convivência social. Os Romanos necessitavam de ocupar os tempos livres e efetuavam espetáculos de entretenimento e comida para a população como forma de a manter ocupada. Conhecidos como "bread and circuses", estes 
espetáculos eram muitas vezes de violência, de simulações de guerra, incluindo animais e seres humanos. Constroem- se nessa época grandes arenas e parques, com capacidade para milhares de pessoas,como é o caso do "The Circus Maximus" que podia albergar 385000 pessoas. (Torkildsen, 1992)

Após o colapso do Império Romano, tornou-se perigoso viajar, vivendo- se uma época conturbada. Os mercadores procuravam novos negócios e trabalhavam intensivamente em busca de novas oportunidades, pelo que se abriu aqui uma porta para o "Turismo de negócios". Na verdade, viajava-se nesta época com sentido de obrigação ou dever, e, saem aqui favorecidas as viagens domésticas. Viajar pelo simples prazer de desfrutar da viagem era considerado tempo perdido, sendo que nesta época o tempo de descanso era somente associado a uma "pausa no trabalho" Holloway, 1994.

O Séc. XVI, promove o aparecimento das viagens de longa distância que ao implicarem a necessidade de alojamento dos viajantes e de repouso para os cavalos, fomentavam os arrendamentos aos viajantes.

No Séc. XVII, no reinado de Elisabeth I de Inglaterra instaurou-se um incentivo para que os jovens membros da corte, homens, se deslocassem para terminar a sua educação no estrangeiro, predominantemente em França ou Itália. Esta deslocação tinha a duração média de três anos, os jovens eram acompanhados por um tutor. Estas viagens eram comummente designadas por "Grand Tour". Os jovens aproveitavam para conhecer a cultura e a vida de grandes cidades como Veneza ou Paris, dando grande impulso às viagens (Holloway,1994).

O mar, um dos grandes elementos de atração turística dos nossos dias, só começou a ganhar preponderância turística com o Turismo de saúde, a partir do Séc. XVIII, começou a ser promovido enquanto beneficiador de saúde. Até então apenas se usava a sua água salgada para beber. Alguns hotéis na costa inglesa começaram a atrair visitantes oferecendo a cura pela ingestão de água do mar e promovendo banhos de imersão. No período inicial de promoção do mar, a adesão não era significativa.

A Revolução Industrial no Séc. XIX é fator de grandes mudanças no trabalho das pessoas, novos fatores servem de motivação e encorajamento às viagens. Surgem mudanças laborais que permitem a possibilidade de viajar, entre as quais destacamos: o tempo para férias; a generalização do salário mensal; a melhoria dos meios de transporte e a otimização de lugares de acolhimento no destino da viagem. As pessoas continuam a viajar por prazer, mas "nasce" a necessidade de conhecer outros locais, culturas e pessoas. As linhas de caminho-de-ferro são um importante meio de ligação entre os grandes centros e as industrias. Ao iniciarem o transporte de pessoas para os hotéis de beira-mar, levam a uma forte expansão da ferrovia. O sucesso dos caminhos-de-ferro e do vapor acompanhou o declínio dos transportes em carruagem. As atividades ao ar livre, neste século de novidades, são uma motivação. A bicicleta é uma das novas forma de deslocação e motiva as pessoas a praticarem um Turismo amigo do ambiente que gera status e saúde ( Holloway,1994). Em 1872, 
Thomas Cook organizou a primeira viagem à volta do mundo, alimentando o desejo da descoberta na sociedade da época. A Revolução Industrial traz para os trabalhadores o direito a férias, férias pagas e folgas. No entanto, em 1900, o vazio legal sobre o assunto pactua com a inexistência de legislação sobre a duração do trabalho semanal ou sobre férias remuneradas. Entre 1900 e 1914, este quadro alterou-se profundamente, sobretudo na Europa Central, que acordou convenções coletivas de trabalho que davam direito a férias e férias pagas. Este cenário será mais tarde um grande impulsionador do Turismo. ( Boyer,2003)

Até à década de 1960, o Turismo mundial é reconhecido fundamentalmente como a prática de atividades de lazer e recreio.

Nos anos 1990 a sociedade sentiu uma acentuada mudança em termos comportamentais, com o aumento do rendimento das famílias, o crescimento das economias, as novas tecnologias, transportes e comunicações. As viagens tornaram-se acessíveis aos cidadãos comuns, o que permitiu a sua popularização e a consequente facilidade de deslocação. Viajar é nesta época um "bem" adquirido, presente no quotidiano e na vida das pessoas. O "Turismo de massas" prevalece permitindo aos turistas a escolha de locais inter - continentais, bem como a procura por um clima e temperaturas tropicais, oferecidos por oportunidades de baixo custo. Esta conjuntura possibilita ainda que grandes hotéis se expandam para novos países, com o intuito de oferecer aos seus clientes a mesma qualidade que têm nas grandes metrópoles. Viagens com propósitos culturais ou de conhecimento do património em cidades como Londres, Paris ou Roma, cruzeiros em rios, ou visitas a parques temáticos, como é o caso da Disneyworld, são experiências que o comum cidadão pode passar a desfrutar no mercado turístico. A indústria de Turismo assegurou também produtos que satisfizeram a procura de massas existente (Holloway, 1994).

O Turismo ganha uma nova dimensão comercial, impulsionado por novos conceitos, novos destinos, e um valor económico crescente a nível mundial, que gera rendimentos, emprego e equilíbrio nas balanças de pagamentos dos países (Costa, 2013). A evolução do Turismo, com o desenvolvimento ocorrido no virar do século XX para o século XXI, permite, segundo Costa, (2013 pag. 78-97) definir um modelo económico de Turismo baseado em três grandes realidades:

\footnotetext{
"Crescimento Económico: os níveis do crescimento do Turismo em termos mundiais continuaram imparáveis a partir dos anos 1990, mesmo durante a fase de contração económica vivenciada pelo mundo durante a primeira fase do seculo XXI: O número de chegadas internacionais continuou a crescer, e todas as previsões na área apontam, mesmo com algumas oscilações, para uma expansão do Turismo nas próximas décadas; Generalização mundial: O Turismo como atividade económica e social tem vindo a generalizar-se a quase todos os países, que têm vindo a "descobrir" o seu potencial em termos de crescimento e desenvolvimento; Dinamização de bases económicas locais: o efeito de disseminação do Turismo dentro das economias locais tem vindo a processar-se num autêntico efeito de "mancha de
} 
óleo". O Turismo tem vindo a deixar de ser entendido numa perspetiva de economia restrita aos subsectores do alojamento e da restauração, para passar a compreender sistemas económicos mais alargados e com vastas repercussões económicas, que compreendem, ainda, os transportes, os operadores turísticos, guias e agentes de viagens, o aluguer de automóveis, os serviços recreativos, e os serviços culturais. Estes sete subsectores do Turismo são atualmente contabilizados dentro de um sistema estatístico próprio, designado por "Conta Satélite do Turismo".

O Turismo cresce, em termos de complexidade da procura, tendências, oferta, industria, gestão e instrumentos de planeamento, o seu desenvolvimento em torno de produtos turísticos é substituído por uma nova perspetiva de valorização das experiências e sensações adquiridas pelos turistas nos locais que visitam. Esta é uma nova realidade do Turismo, que promove uma nova indústria, novos mercados turísticos, novas formas e novos instrumentos de gestão e planeamento no sector turístico. 0 Turismo é considerado, à data de realização desta pesquisa, como uma das maiores indústrias do mundo. Por força do seu relacionamento e interligação com todos os outros sectores da vida (económico, social, cultural, ambiental e político), torna-se difícil estabelecer uma definição clara e abrangente do termo Turismo. Muitos estudos consideram que uma definição universal será quase impossível de alcançar, e que seria mais realista a aceitação de várias definições com propósitos específicos. (UNEP - Priority Actions Programe2009)

O Turismo pode, segundo a Comissão Europeia, desempenhar um papel importante no desenvolvimento das regiões Europeias, contribuir para o desenvolvimento local, criando empregos e minimizando possíveis declínios industriais ou rurais. De extrema importância nas regiões mais remotas, e afastadas dos centros económicos, é muitas vezes a garantia de criação de emprego ou uma fonte de rendimento para a população residente (Eurostat - European Commission 2013a).

\subsection{Origens e Evolução do Turismo em Portugal}

Portugal é um país com aproximadamente 10 milhões de habitantes (Censos, 2011), foi desde os primórdios uma atração enquanto país para diversas civilizações. Celtas, Gregos, Romanos, Visigodos ou Mouros passaram por estas terras ao longo de vários séculos de história, conquistas e batalhas. Nos séculos XV e XVI, Portugal avança no conhecimento do mundo com a época dos "Descobrimentos", e desvenda novos destinos, novas rotas, novos mercados e novas civilizações (rota marítima para a Ásia, África e Américas), expandindo a fé e o cristianismo.(Costa, 2013). As civilizações que povoaram Portugal ou a "Ibéria" (a península onde se localiza Portugal e Espanha), criaram infraestruturas importantes para o desenvolvimento, de onde salientamos os banhos (atualmente termas), as arenas ou os ginásios. Estas podem ser consideradas as "Raízes do Turismo em Portugal"(Costa, 2013). Sintra e Évora nessa época tornaram-se populares locais de lazer da aristocracia. 
Saraiva (1999) considera que o período mais antigo e importante do Turismo em Portugal data da época dos Descobrimentos, altura em que Henry, o navegador, decide criar a escola de navegação de Sagres, enviando vários grupos para o mar, na descoberta de novas rotas.

Em 1840, nasce a primeira operadora de viagens em Portugal, a "Viagens Abreu", responsável entre outras coisas pela organização de viagens Brasil- Portugal. Em 28 de Fevereiro de 1906 é aprovada a constituição da Sociedade Propaganda de Portugal, e em 4 de Julho do ano seguinte são aprovados os seus estatutos, dando-se assim início às primeiras atividades institucionais do Turismo Português (Pina, 1988). Com a Implantação da República em 1910, e numa época inconstante politicamente, Portugal consegue trazer para Lisboa a organização do IV Congresso Internacional de Turismo (12-20 Maio de 1911), que acaba por ser uma importante prova dada pela comunidade internacional de aceitação do novo regime político.

Após o término da 1. a Grande Guerra Mundial, a Sociedade Propaganda de Portugal ainda consegue algum dinamismo e algumas parcerias, que resultam na abertura em Paris da Primeira Casa de Portugal. Esta iniciativa não passa contudo para além dos anos 30, terminando assim um projeto pioneiro, na história do Turismo.

Em 1911, em congresso nasce, no Ministério do Fomento, o Conselho de Turismo associado a uma Repartição de Turismo. Até 1940 vive dias tempestuosos, devido à instabilidade política e social, à 2. a Grande Guerra, à guerra civil de Espanha e à falta de recursos humanos e financeiros. Ainda assim Portugal assiste ao nascimento de dois centros de Turismo internacional, em Fátima e no Estoril (um projeto que nasce de raiz por "extensão da Costa do Sol"). Em 1932 a estância do Estoril consegue atrair

2.500 hóspedes. Em 1934, António Ferro, citado na mesma obra, apresenta um projeto de difusão da imagem do país, e dá relevo ao Turismo "mormente pelo extraordinário potencial que a sua típica multidisciplinaridade representava". Assim, António Ferro extravasa de forma arrojada as fronteiras de uma nova visão multidisciplinar em Turismo, considerando que "papel bàsico se confina, de resto, ao suporte logístico duma prática de ocupação animada e cultural dos tempos livres, que dela carece para os fins mais prosaicos, mas não menos essenciais de providenciar facilidades tais como o transporte, o alojamento ou a restauração". A partir de 1944, Ferro consegue mesmo colocar em prática o seu projeto, conciliando a cultura, a comunicação social e o Turismo, e oferecendo o conceito de "diferença" para publicitação do país.

Em 1964, Portugal atinge pela primeira vez um milhão de entradas de estrangeiros no país, e consequentemente, o Turismo é incluído num Plano de Fomento, intercalar (1965-1967).

Vivem-se anos conturbados, com a revolução de Abril de 1974. A 23 de Dezembro de 1975, o VI Governo provisório, temendo que as nacionalizações fossem catastróficas para o sector, declara o Turismo "como atividade privada e prioritária". Ainda as- 
sim as quedas de $50 \%$ das entradas de estrangeiros no país foram desanimadoras para o sector. Em 1986, a criação do Instituto de Promoção Turística vem projetar novamente o país internacionalmente, mostrando uma nova imagem e novas áreas promocionais e, em 1986, nasce o Plano Nacional do Turismo. Mesmo com algumas limitações, este Plano veio propor a atuação concertada em diversas áreas chave, nomeadamente do ordenamento territorial, termalismo, animação, formação, investimento e promoção (Pina, 1988)

No ano 2001, Costa (1996) refere o forte crescimento do sector do Turismo em Portugal, com a introdução de novas estratégias de reestruturação em várias organizações nacionais do sector. O Turismo, nesta fase da história, apresenta um crescimento muito acentuado, nomeadamente em algumas zonas do país como o Algarve, a zona de Lisboa e a Madeira. Este cenário conflui, no entender do autor, a um crescimento em quantidade que descura, no entanto, a qualidade devido à excessiva concentração turística nos locais referidos.

É importante a existência de uma postura pró-ativa por parte do país e das pessoas ligadas ao Turismo como forma de capitalização de novas oportunidades de negócio provenientes da triplicação do número de pessoas que aqui passa férias, ressalvando o enorme potencial de negócio no sector turístico. (Rsamos, 2014)

\section{A DIMENSÃO TURÍSTICA}

\subsection{A Importância do Turismo a Nível Mundial}

O Crescimento do Turismo nas últimas décadas, e a tomada de consciência da sua importância para a economia e para o emprego dos países, nomeadamente pela criação de valor acrescentado e receitas públicas, origina a que diversos organismos internacionais como as Nações Unidas, a OMT e a Eurostat se reúnam e trabalhem no sentido de quantificar os efeitos do Turismo, para que os agentes económicos possam tomar as decisões com base em factos macroeconómicos e micro- económicos. Atenta à necessidade de um sistema atual responsável a nível internacional que avaliasse os dados nacionais, a Eurostat participou no processo de atualização que revê o SEC 95 (Sistema Europeu de Contas) e o torna comum, eliminando a versão europeia do SNC (Sistema de Normalização Contabilística) 1993, em que figuram como principais características das contas: a Universalidade, a Transparência, a Harmonização e a Flexibilidade.(EUROSTAT 2014)

A Conta Satélite em Turismo (CST), segundo a Organização Mundial de Turismo (OMT) 2008, "baseia-se na análise pormenorizada de todos os aspetos da procura de bens e serviços associados à atividade dos visitantes; observação da interface operacional com o fornecimento desses bens e serviços na economia; assim como a descrição de como a oferta desses bens e serviços interage com outras atividades económicas." O consumo Turístico tem a mesma definição formal que o gasto turístico, no 
entanto o conceito de consumo turístico na CST vai mais além que o conceito de gasto turístico, porque além da soma que é paga pela aquisição de objetos, bens e serviços de consumo (transações monetárias - o objetivo do gasto turístico), também se incluem serviços associados, como as férias por conta própria ou outros consumos imputados (United Nations, 1992).

A Recomendação de 1991 de Ottawa (United Nation, 1992) limita o âmbito do consumo turístico aos visitantes que realizam viagens no seu país de origem, para o seu país de origem ou desde o seu país de origem e classifica o consumo turístico e as formas de Turismo.

O Turismo a nível mundial é um dos sectores com maior crescimento, dados oficias da UNWTO World Tourism Barometer (2013), e relativos ao ano 2012, demonstram, claramente a sua dimensão e potencial, verificou-se que as chegadas internacionais de Turismo - foram superiores a 1 bilião, com um crescimento de 4\%, o maior crescimento verificou-se na Ásia e Pacifico (7\%), seguido da África (6\%), as Américas (5\%), e a Europa (3\%) com um incremento de chegadas de 18 milhões de pessoas. O Médio Oriente sofre um decréscimo de chegadas de aproximadamente $5 \%$. A maioria das viagens foi feita para lazer ou atividades recreativas, (52\%), seguindo-se a visita a amigos e viagens religiosas com $27 \%$, e o motivo profissional com $14 \%$, o motivo de viagem não especificado ficou pelos $7 \%$. As receitas do Turismo Internacional cresceram $4 \%$, o que traduz um novo recordee em termos reais, correspondendo a um aumento de 837 biliões de euros. Por Região, a Ásia e o Pacifico, as Américas e África registaram um acréscimo de $6 \%$ a nível de receitas, ao passo que a Europa verificou um aumento de $2 \%$. No Médio Oriente as receitas têm um decréscimo de $2 \%$, devido à contínua turbulência na região. A Europa continua a reter a quota mais elevada de receção de turistas, cifrada nos $43 \%$ no ano 2012, seguida da Ásia e Pacífico com 30\% e das Américas $20 \%$. Os gastos dos visitantes em alimentação, estadia, transportes, entretenimentos e compras criam um leque de oportunidades de desenvolvimento para os países visitados. Os destinos mais visitados no ano 2012 foram por ordem de ranking, 1.․ Estados Unidos, 2. Espanha, 3. França, notando-se aqui alterações relativas ao ano transato, onde a Alemanha, agora em 70 lugar, tinha estado em 1.ㅇ lugar do ranking no ano anterior.

Os resultados regionais, e analisando os dados obtidos na Europa, o crescimento foi de $3 \%$, algo inferior aos $6 \%$ registados no ano 2011, provavelmente pela crise económica que a flagelou no ano 2012. Neste ano, a Europa recebeu um total de 534 milhões de chegadas de turistas, o que representa 18 milhões a mais que 2011, e um acréscimo de $2 \%$ de receitas entradas, correspondente a 356 biliões de euros. Este incremento foi mais acentuado na Europa Central e oriental, com um acréscimo de $7 \%$ de entradas, onde países como a Geórgia (36\%) ou a Federação Russa (13\%) foram impulsionadores deste acréscimo. O Norte da Europa cresce apenas 1\%, e os países mediterrânicos consolidam as suas posições de crescimento, como é o caso de Espanha (3\%) e Portugal (4\%). Realça-se que o acréscimo de visitas na Europa neste 
ano, pode dever-se em parte, a eventos desportivos, como é o caso do Campeonato Europeu de Futebol na Polónia e Ucrânia ( a Polónia registou um incremento de Turismo na ordem dos $11 \%$, ao passo que a Ucrânia viu o seu número de visitantes aumentar em 7\%), e dos Jogos Olímpicos e Paraolímpicos de Verão em Londres. No mercado mundial do Turismo, a China gastou um valor recorde no ano 2012, representando um total de 102 biliões de dólares.

Dados de 2013, datados de 20 de Janeiro de 2014, referem: "O Turismo internacional supera as expectativas com as chegadas a aumentar 52 milhões em 2013, e as Chegadas de turistas internacionais a crescer $5 \%$ em 2013 , atingindo um recordee de 1.087 milhões de chegadas, de acordo com o mais recente Barómetro OMT Mundial do Turismo. Apesar dos desafios económicos globais, os resultados do Turismo internacional foram bem acima das expectativas, com um aumento de 52 milhões de turistas internacionais em 2013. Para 2014, a OMT prevê um crescimento de $4 \%$ a 4,5\%. A procura de Turismo internacional foi mais forte para os destinos da Àsia e Pacífico (+6\% ), África ( $6 \%$ ) e Europa (+5\%). As principais sub-regiões foram o Sudeste da Àsia (10 \%), a Europa Central e Oriental (+7\%), Europa do Sul e Mediterrânea (+6\%) e África do Norte (6\%).O sector do Turismo tem mostrado uma notável capacidade de se adaptar às novas condições de mercado, aos desafios económicos e políticos, consolidado o crescimento e a criação de emprego em todo o mundo."(UNWTO Communications Programme 2015)

\subsection{O Desenvolvimento Turístico em Portugal}

Portugal é um dos maiores destinos turísticos mundiais. A atividade turística emprega aproximadamente meio milhão de pessoas, e tem um forte impacto nas exportações nacionais. Em 2014 os dados provisórios da Organização Mundial de Turismo apontam para um aumento das chegadas de turistas internacionais de $4,4 \%$, correspondendo a 1 134,7 milhões de turistas. De acordo com os dados do Banco de Portugal relativos à rubrica "Viagens e Turismo" da Balança de Pagamentos em 2014, as receitas aumentaram relativamente ao ano anterior $(+12,4 \%)$, superando o patamar dos 10 mil milhões de euros (10 394 milhões de euros). O motivo principal que despoletou a concretização de viagens foi a "Visita a familiares ou amigos", que correspondeu a 8,2 milhões de deslocações em 2014 , concentrando $46,0 \%$ do total $(46,9 \%$ em 2013). As viagens por "Lazer, recreio ou férias" representaram $40,6 \%$ das viagens turísticas (41,5\% em 2013) enquanto as viagens "Profissionais ou de negócios" agregaram $8,7 \%$ do total de viagens (7,3\% em 2013). Os meios de alojamento turístico, na sua globalidade (hotelaria, Turismo no espaço rural e de habitação e ainda o alojamento local), disponibilizaram em julho de 2014 uma oferta de 3578 estabelecimentos e 342,5 mil camas $(+7,0 \%$ e $+5,0 \%$ que em 2013$)$. O número de hóspedes fixou-se em 17,3 milhões e as dormidas em 48,8 milhões, correspondendo a incrementos de $13,9 \%$ e $12,1 \%$. A hotelaria (hotéis, hotéis-apartamentos, pousadas e quintas da Ma- 
deira, aldeamentos turísticos e apartamentos turísticos) representou 83,2\% da capacidade de alojamento (camas), $86,5 \%$ do total de hóspedes e $89,2 \%$ das dormidas. 0 Reino Unido foi o principal mercado emissor ( $24,2 \%$ das dormidas de não residentes) e apresentou um crescimento de 9,5\%. A Alemanha e a Espanha, com quotas de $13,5 \%$ e $11,1 \%$, apresentaram igualmente evoluções positivas (7,6\% e $15,4 \%$, respetivamente). A estada média global foi de 2,90 noites $(-1,4 \%)$ e a taxa líquida de ocupação-cama fixou-se em $45,2 \%$ (+2,6 p.p.).

Em 2014 a atividade económica revelou sinais de recuperação. O Produto Interno Bruto (PIB) aumentou 0,9\% em volume, após uma variação negativa de $1,6 \%$ no ano anterior. A taxa de desemprego diminuiu, situando-se em $13,9 \%$ (16,2\% em 2013). A taxa de inflação passou de $+0,3 \%$ em 2013 para -0,3\% em 2014. O indicador de confiança dos consumidores manteve a tendência genericamente crescente que já se tinha verificado no ano anterior, aumentando ao longo do ano e com estabilização em dezembro. $\mathrm{O}$ indicador de clima económico das empresas continuou a registar crescimento no seguimento do ano anterior, estabilizando a partir do início do 2 o semestre e evidenciando ligeira redução nos dois últimos meses do ano. Relativamente às empresas de Serviços, o indicador de confiança registou continuidade na tendência de crescimento do ano anterior (INE, 2015).

\section{TENDÊNCIAS E EVOLUÇÃO TURÍSTICA}

Buhalis (2006), ao fazer uma análise sobre o futuro da indústria do Turismo, em 2006, mencionam que a sua evolução é o resultado da evolução do conceito de Consumo, e das tendências dos consumidores, que estão mais informados, e procuram experiências mais sofisticadas. Esta evolução requer a criação de novos produtos e novas estratégias de gestão e organização do Turismo. A evolução é inevitável, e influenciada pelos fatores externos ao Turismo e pela globalização do sector. Provavelmente, mais do que a maioria dos sectores de atividade, o sector do Turismo está a enfrentar uma mudança acentuada e a um ritmo galopante. Para Costa (2013) esta mudança contribui para a criação de um novo consumidor de Turismo. Este novo consumidor de Turismo não é apologista de Turismo de massas, ou do marketing massivo. Na realidade, este novo turista procura o Turismo diferenciado, um tratamento personalizado, conhecer outros modos de vida e experienciar vivências autênticas e genuínas. Trata-se de um turista informado, na vida de quem as tecnologias de informação têm uma presença plena. Este novo turista sabe o que procura, respeita o ambiente e a comunidade. O Turismo tradicional para sobreviver deverá adaptar-se, tornar-se melhor e mais competitivo, e estar preparado para um mercado turístico mais volátil; na opinião destes autores.

Segundo Costa (2013), a globalização é uma competitividade sustentável, pilar de mudanças em planeamento e organização turística e com um impacto estruturante nos componentes e na estrutura da oferta turística. Nos territórios rurais, na área 
agrícola e no Turismo o fator "terra" representa um elemento vital, contribuindo para experiências autênticas e para a diversificação dos destinos, sendo fundamental incorporar o segmento de Vinho e Gastronomia nas ofertas turísticas rurais. Relativamente ao Turismo das Zonas Costeiras, este deverá procurar uma solução viável de combate a sazonalidade, criando novas ofertas, novos produtos, e novos mix de produtos adaptados às necessidades do mercado. A ausência de uma política coordenada e coerente é, na opinião dos autores, o que mais afeta o Turismo a nível europeu.

Em "Turismo nos Países Lusófonos" Costa (2013), salientam a evolução turística dando enfoque à existência de novos consumidores e consequentemente novas tendências da procura, impulsionadas pela transformação do comportamento do consumidor. A isto se juntam as novas tendências do Turismo, na procura de novos mercados, novos produtos (Turismo espacial, por exemplo), novas tendências a nível demográfico, social, económico ou de investigação. Esta tendência evolutiva pressupõem a necessidade de uma nova gestão, mais global, inovadora, e de parceria, utilizando novos instrumentos e atracões, e apoiando-se em novas ferramentas de planeamento e desenvolvimento do território, centradas no consumidor.

A UNWTO Tourism Towards atualizou a sua perspetiva de desenvolvimento em Turismo para as décadas de 2010-2030, e substitui assim, a anterior visão do Turismo 2020. Esta é uma previsão essencialmente quantitativa, tendo como base a procura internacional, mas tendo sempre presentes fatores que influenciaram e moldaram o Turismo internacional ao longo do tempo, de foro social, politico, económico, ambiental e tecnológico. Assim, e de acordo com as previsões atualizadas, espera-se um incremento de turistas na ordem dos 43 milhões por ano, o que representará em 2020, 1.4 biliões e em 2030 o valor de 1.8 biliões. O grande crescimento deverá verificar-se na Ásia e Pacífico, onde se espera uma receita de 535 milhões em 2030. Para a Europa a estimativa é que passe dos 475 milhões para os 744 milhões em 2030.(UNWTO World Tourism Barometer 2013)

O Turismo como fator de desenvolvimento mundial é um dos principais setores de atividade a contribuir para o crescimento de $3.4 \%$ da economia mundial. Observou-se um aumento generalizado das receitas do Turismo entre as várias regiões mundiais, salientando-se o Médio Oriente ( $+5,7 \%$ face a $-7,0 \%$ em 2013) e a Àsia e Pacífico $(+4,2 \%)$. Na Europa, que representou $40,9 \%$ do total, as receitas aumentaram 3,6\%, menos que no ano anterior ( $+4,2 \%)$. Em África as receitas tiveram um aumento mais intenso (+3,4\% em 2014 e $+2,7 \%$ em 2013), enquanto nas Américas (+3,0\%) se verificou uma desaceleração de 2,0 p.p. no crescimento das receitas ( Instituo Nacional de estatística,2015).

\section{CONSIDERAÇÕES FINAIS}

O Turismo é um agente indutor do desenvolvimento transversal e da evolução da sociedade. Economicamente é um dos setores que mais cresce a nível mundial e que 
mais oportunidades oferece de investimentos de sucesso. A evolução do Turismo permite ou tem a capacidade de permitir que as populações conheçam a sua historia, as suas origens e que possam se reinventar e transcender em termos de desenvolvimento e ideias inovadoras. O Turismo funciona como um "motor" das economias, agregando princípios base de genuinidade, tradição, cultura e de novas estratégias de gestão e organização do setor.

O Turismo do futuro prevê-se que substitua as rotinas diárias por novos conceito de satisfação, felicidade e qualidade de vida que serão a chave para a produtividade e a premissa das sociedades do futuros em termos de inovação e criatividade. Em plena era das tecnologias da informação é fundamental a adaptação ao desenvolvimento sustentado e sustentável, económica, social e ambientalmente.

Em Portugal, o Turismo é um dos motores da economia nacional. As previsões são de crescimento num país com culturas e tradições variadas onde a principal aposta deve ser no autentico e diferenciador que nos distingue como país, onde a multiculturalidade é um fator determinante e convidativo. A principal caraterística que diferencia o país é a sua singularidade, a sua população hospitaleira, a gastronomia e o clima ameno.

\section{REFERÊNCIAS}

BOYER, Marine (tradução). História do Turismo de Massas. Edusc/ Edufba. Brasil: EDUSC / EDUFBA, 2003

BUHALIS, Dimitris. Tourism Business Frontiers - Consumers, products and industry. Elsevier, 2006

COSTA, Carlos Towards the Improvement of the Efficiency and Effectiveness of Tourism Planning and Development at the Regional Level: Planning, Organisations and Networks: The Case of Portugal, Tese Doutoramento, Universidade de Surrey, Surrey, 1996.

COSTA, Carlos (Eds.) Turismo nos Países da lusofonia: conhecimento, estratégia e territórios, Vol. I, Editora Escolar, Portugal, 2013

COSTA, C. "Tourism Planning and Organization in Portugal" in European Tourism Planning and Organizations Systems, Chanel View, London Chanel View, 2013

COSTA, Carlos. Trends in European Tourism Planning and Organisation: Aspects of Tourism, Channel view Publications - British Library, 2013

EUROSTAT. - Statistics Explained. Eurostat, European Comission, 2013a

EUROSTAT. 'Building the System of National Accounts - Context' - Statistics Explained. Eurostat, European Comission 2014

HOLLOWAY, J. The Business of Tourism, Quarta edição, Longon Group Limited, England, 1994

INE - Estatísticas do Turismo de 2014 - Instituto Nacional de Estatística, I. P., Lisboa Portugal, 2015 
OMT - Organização Mundial do Turismo. Tendências do Turismo Internacional, OMT, Madrid, 2008

PINA, Paulo, Portugal - O Turismo no Sec. XX. lucidus. Lucidus, 1988

SARAIVA, José. História Concisa de Portugal. Publicações Europa - América. Men Martins, 1999

RAMOS, Dina. Turismo Costeiro em Zonas Rurais - Um Novo Conceito em Turismo, Tese Doutoramento, USAL, Universidade de Salamanca, 2014

TORKILDSEN, George.. Leisure and Recreation Managment. 3.a edição. UK: E \& FN Spon, an imprint of Chapman \& Hall, 1992

UNEP - Priority Actions Programme. Sustainable Coastal Tourism - An Integrated Planning and Management Approach, UNEP Manuals on Sustainable Tourism, 2009

UNITED NATIONS. Department of Economic and Social Affairs. Agenda 21, United Nations, 1992

UNWTO World Tourism Barometer - Tourism Market Trenders, 2013

UNWTO Annual Report 2014 - Published by the World Tourism Organization (UNWTO), Madrid, Spain. First printing: 2015

UNWTO World Tourism Barometer 2013- A UNWTO Tourism Towards 2030; General Assembly 19 th Session, Gyeongju Republic of Korea, 2011

Artigo recebido em 31 de outubro de 2016.

Aprovado em 27 de julho de 2017. 